\title{
Atrial Natriuretic Peptide Attenuates Ischemia/Reperfusion-Induced Renal Injury by Reducing Neutrophil Activation in Rats
}

\author{
Kousuke Chujo, ${ }^{1}$ Masaaki Ueki, ${ }^{1}$ Takehiko Asaga ${ }^{1}$ and SAtoshi Taie ${ }^{1}$ \\ ${ }^{1}$ Department of Anesthesiology, Faculty of Medicine, Kagawa University, Kagawa, Japan
}

\begin{abstract}
Activated neutrophils have been implicated in the development of ischemia/reperfusion (I/R)-induced renal failure. Cytokine-induced neutrophil chemoattractant-1 (CINC-1), a major factor in acute inflammation, is responsible for the activation of neutrophils and for neutrophil chemotaxis to sites of injury. Atrial natriuretic peptide (ANP), a hormone synthesized by the cardiac atria, was shown to possess anti-inflammatory potential due to its potency to inhibit the production of inflammatory mediators. We examined whether the human form of ANP attenuates I/R-induced renal injury by reducing neutrophil activation in a rat model. Male Wistar rats weighing 200-240 g were observed for $24 \mathrm{~h}$ after reperfusion following 45-min renal ischemia. Rats were intravenously administered alphahuman ANP ( $\alpha$-hANP, $0.2 \mu \mathrm{g} / \mathrm{kg} / \mathrm{min}$ ) beginning immediately after ischemia and continuing for $2 \mathrm{~h}$ after reperfusion. CINC-1 and myeloperoxidase (MPO) concentrations were measured to assess activation of the infiltrating neutrophil. Blood urea nitrogen and serum creatinine and urinary $\mathrm{N}$-acetyl $\beta$-d-glucosaminidase (NAG) were measured as indicators of glomerular function and as a specific indicator of proximal tubular function, respectively. $\alpha$-hANP significantly inhibited I/R-induced increases in renal CINC-1 and MPO concentrations. $\alpha$-hANP also reduced I/R-induced increases in the concentrations of blood urea nitrogen and serum creatinine, and improved histopathologic changes, including acute tubular necrosis. These findings indicate that $\alpha$-hANP attenuates I/R-induced acute renal injury, at least in part by reducing neutrophil activation, and may be useful in surgeries, associated with renal ischemia, as well as in renal transplantation. —— human atrial natriuretic peptide; neutrophils; kidney; ischemia/reperfusion; cytokine-induced neutrophil chemoattractant- 1 .
\end{abstract}

Tohoku J. Exp. Med., 2008, 215 (3), 257-266.

(C) 2008 Tohoku University Medical Press

Ischemia/reperfusion (I/R) injury is one of the most important pathological mechanisms in the development of acute renal failure associated with renal transplantation, aortic cross-clamping of suprarenal aortic aneurysms and septic shock (Bonventre 1993). The mechanisms underlying
I/R damage to the kidneys are most likely multifactorial and interdependent, and involve hypoxia, vascular endothelial injury, inflammatory responses, and radical-induced damage (Williams et al. 1997). In order to be able to make substantial improvements in the current therapeutical

Received March 23, 2008; revision accepted for publication May 30, 2008.

Correspondence: Masaaki Ueki, Department of Anesthesiology, Faculty of Medicine, Kagawa University

1750-1 Ikenobe, Miki-cho, Kita-gun, Kagawa 761-0793, Japan.

e-mail: mueki@med.kagawa-u.ac.jp 
approaches, a better understanding of the molecular mechanisms for this injury is required. Activated neutrophils have been implicated in the pathophysiology of I/R-induced acute renal injury. Activated neutrophils adhere to vascular endothelial cells in the vasa recta of the outer medulla (Thadhani et al. 1996). When activated neutrophils infiltrate into tissue, they release a variety of inflammatory cytokines and reactive oxygen species, leading to tissue injury (Harlan 1985). Cytokine-induced neutrophil chemoattractant-1 (CINC-1), a major factor in acute inflammation, is responsible for the activation of neutrophils and for neutrophil chemotaxis to the sites of the injury (Watanabe et al. 1992). Thus, agents that inhibit activation or adhesion of neutrophils might prevent or attenuate renal $\mathrm{I} / \mathrm{R}$ injury in rats.

Atrial natriuretic peptide (ANP), a hormone secreted mostly by cardiac myocytes (De Bold 1979), is a potent natriuretic, diuretic and vasodilatory peptide that contributes to blood pressure and volume homeostasis. ANP is released by myocytes in response to atrial distention. After binding to a specific receptor, ANP acts through the generation of a second intracellular messenger, cyclic guanosine monophosphate. ANP was shown to possess anti-inflammatory potential due to its potency to inhibit the production of inflammatory mediators (Kiemer et al. 2000). ANP has been used clinically for the treatment of heart failure (Saito et al. 1987). ANP has been shown to improve renal function in clinical ischemic acute renal failure (ARF) (Rahman et al. 1994; Valsson et al. 1994). However, the mechanisms of the renoprotective effects of ANP remain unclear.

Therefore, this study evaluated the ability of the human form of ANP to attenuate the decrement in renal function produced by 45 -min renal ischemia in a rat model, with the main focus on the activation of neutrophils.

\section{Material and Methods}

\section{Animal preparation}

All surgical procedures and experimental protocols were approved by the Animal Care and Use Committee of Kagawa University Faculty of Medicine. A total of 156 male Wistar rats (Clea Japan, Osaka, Japan), weigh- ing 200 to $240 \mathrm{~g}$, were used in this study. Rats were fasted for $12 \mathrm{~h}$ before surgery. Rats were anesthetized with an intraperitoneal injection of sodium pentobarbital (50 $\mathrm{mg} / \mathrm{kg}$; Abbott Laboratories, North Chicago, IL, USA). The alpha-human ANP ( $\alpha$-hANP) was a generous gift from the Daiichi Sankyo Company (Tokyo, Japan).

\section{Renal ischemia/reperfusion}

A right nephrectomy was performed via a dorsal incision with infiltrating anesthesia of $1 \mathrm{ml}$ of lidocaine hydrochloride (AstraZeneca, Wilmington, DE, USA). The left kidney and renal vessels were exposed via a dorsal incision with infiltrating anesthesia of $1 \mathrm{ml}$ of lidocaine hydrochloride. For the warm ischemia studies, the left renal artery and vein were occluded with a vascular clip for $45 \mathrm{~min}$ and then released, as the kidney will not recover if the injury is prolonged beyond 60 to $90 \mathrm{~min}$ (Takada et al. 1997). Occlusion was verified visually by the change in the color of the kidney, which became a paler shade after occlusion followed by a blush color once reperfusion occurred. One group of rats were subjected to a sham operation (sham-operated) using the identical surgical procedures as for the vehicle group, with the exception that they did not undergo the left renal vessel occlusion with the vascular clip, although they were maintained under anesthesia for duration of the experiment. The animals were then returned to their cages and allowed free access to water. At specified time points, the rats were sacrificed by injections of sodium pentobarbital and lidocaine hydrochloride.

\section{Experimental protocol}

The experimental design was shown in Fig. 1. The animals were allocated randomly into three groups. (i) Sham group. The sham-operated animals underwent identical surgical procedures as were performed in the ANP group, with the exception that they did not undergo left renal vessel occlusion with a vascular clip. (ii) $A N P$ group. $\alpha$-hANP was continuously infused at a rate of 0.2 $\mu \mathrm{g} / \mathrm{kg} / \mathrm{min}$, which was begun immediately after the ischemia and continued for $2 \mathrm{~h}$ after reperfusion. In a series of preliminary studies, different doses of $\alpha$-hANP of 0.2 and $1 \mu \mathrm{g} / \mathrm{kg} / \mathrm{min}$ were administered in order to investigate the effects on renal CINC-1 concentration at $2 \mathrm{~h}$ after reperfusion. The $0.2 \mu \mathrm{g} / \mathrm{kg} / \mathrm{min} \alpha$-hANP dose reduced renal CINC- 1 concentration at $2 \mathrm{~h}$ after reperfusion to a greater degree than was observed for $\alpha$-hANP at $1 \mu \mathrm{g} / \mathrm{kg} / \mathrm{min}$ (Fig. 2B). Thus, $0.2 \mu \mathrm{g} / \mathrm{kg} / \mathrm{min}$ of $\alpha$-hANP was chosen for all subsequent experiments. The 


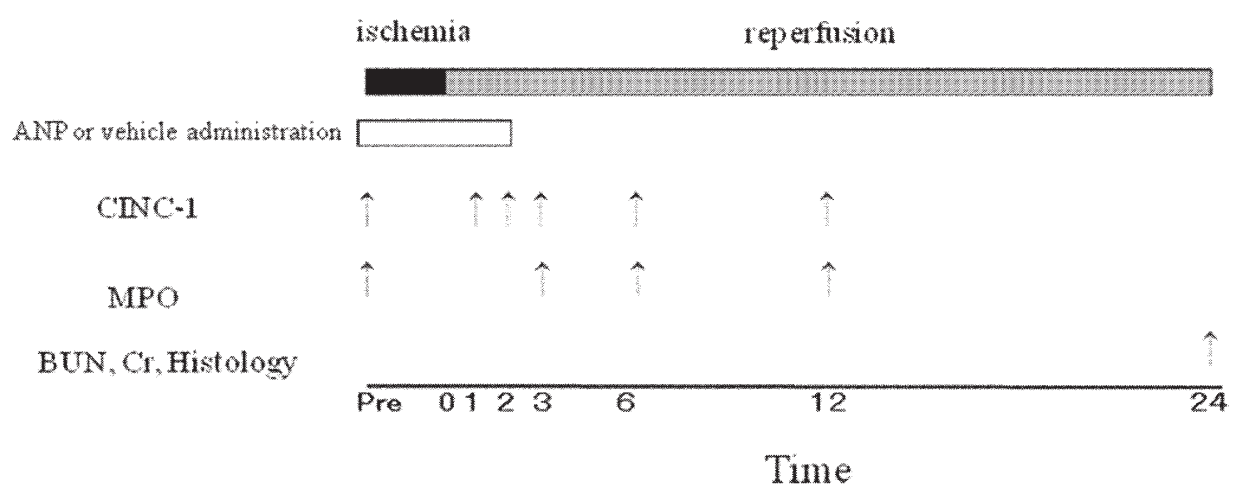

Fig. 1. Experimental design.

Summary of the experimental design showing the sampling times, indicating by upward arrow. $\alpha$-hANP or vehicle (saline solution) were continuously infused, which was begun immediately after the ischemia and continued for $2 \mathrm{~h}$ after reperfusion.

dose of $\alpha$-hANP used in these experiments is the same as is used clinically. The duration of $\alpha$-hANP in this study was based on our previous work that found that renal ischemia/reperfusion injury resulted in a peak increase in the CINC-1 concentration at $2 \mathrm{~h}$ after reperfusion. (iii) Vehicle group. These animals underwent renal ischemia for $45 \mathrm{~min}$ followed by reperfusion. Vehicle (saline solution) was administered in the same manner as $\alpha$-hANP

\section{Enzyme immunoassay for CINC-1 and myeloperoxidase (MPO) concentrations}

A total of 120 rats were used for the CINC-1 and MPO measurements. At various time intervals after the surgery, a kidney was removed for the analysis of the CINC- 1 and MPO concentrations $(n=8$, each time point), immersed in liquid nitrogen, and then maintained at $-80^{\circ} \mathrm{C}$ until evaluation. The concentration of CINC-1 in the rat kidney, which serves as a chemotaxic factor for the activation of neutrophils and chemotaxis to the site of the injury, was measured by ELISA using a rat IL-8 assay kit (Panapharm Laboratories, Kumamoto, Japan). MPO, an enzyme found predominantly in the azurophilic granules of neutrophils, correlates with the number of neutrophils determined histochemically in inflamed tissue and thus, it can be used as an indicator of neutrophil infiltration (Bradley et al. 1982). The MPO concentrations in the kidney were used as an indicator of neurophil infiltration and were measured using a myeloperoxidase ELISA kit (Oxis International Inc, Foster City, CA, USA). At specified time points after $\mathrm{I} / \mathrm{R}$, a kidney was removed and homogenized with a homogenizer (Polytron PT10-35, Kinematika, Luzern, Switzerland) using 0.1 mol/l phosphate buffer ( $\mathrm{pH} 7.4$ ) containing $0.05 \%$ (weight/volume) sodium azide at $4^{\circ} \mathrm{C}$. Homogenates were sonicated for $20 \mathrm{~s}$ and then centrifuged $(2,000 \mathrm{~g}$ for 10 min at $4^{\circ} \mathrm{C}$ ). The supernatants were kept at $-80^{\circ} \mathrm{C}$ until the CINC-1 and MPO levels were measured according to the manufacturers' instructions and expressed as picograms per gram of tissue and nanograms per gram of tissue, respectively.

\section{Measurement of mean arterial blood pressure}

We used 12 rats used for mean arterial blood pressure measurements. The right femoral artery was cannulated and connected to a pressure transducer for measurements of the mean arterial blood pressure $(n=4$, each). Mean arterial blood pressure equals the diastolic pressure plus one-third of the pulse pressure, which is the difference between the systolic and diastolic pressure.

\section{Measurement of biochemical parameters}

A total of 24 rats were used for the measurements of the biochemical parameters and the histopathology. At $24 \mathrm{~h}$ after reperfusion, a $5 \mathrm{ml}$ blood sample and a 1-ml urine sample were collected from rats undergoing renal $\mathrm{I} / \mathrm{R}$ via the femoral artery and urinary bladder, respectively. A $3 \mathrm{ml}$ aliquot for blood urea nitrogen (BUN) and creatinine measurements was centrifuged $(2,000 \mathrm{~g}$ for 3 $\min$ ) to separate the serum, and the plasma supernatants were stored at $-80^{\circ} \mathrm{C}$ until measurements were performed ( $n=8$, each group). The remaining $2 \mathrm{ml}$ of each blood sample was used for the neutrophil count measurements ( $n=5$, each group). For the whole blood samples, the BUN, creatinine, and neutrophils were analyzed commercially (Special Reference Laboratories, Tokyo, 
Japan). The BUN and creatinine concentrations were used as indicators of glomerular function. The urinary concentrations of $N$-acetyl $\beta$-d-glucosaminidase (NAG), a specific indicator of proximal tubular function, also were measured within $24 \mathrm{~h}$ after collection using an NAG test (Shionogi Kit, Shionogi, Osaka, Japan).

\section{Histopathologic evaluation}

At $24 \mathrm{~h}$ after reperfusion, the I/R kidney was removed, placed in formalin, and embedded in wax according to standard protocols. For the light microscopy studies, $5-\mu \mathrm{m}$ sections were cut and stained with hematoxylin and eosin. At $24 \mathrm{~h}$ after reperfusion, random corticomedullary junction fields were observed at a magnification of $\times 400$. Using a method modified from McWhinnie et al. (McWhinnie et al. 1986), histopathologic assessment of the tubular necrosis was determined semiquantitatively by a person who was unaware of the treatment conditions ( $n=4$, each group). From each kidney, 100 intersections were examined, and a score from 0 to 3 was given for the tubular profiles involving an intersection: $0=$ normal kidney; 1 = tubular cell swelling, brush border loss or nuclear condensation, with up to one-third of the tubular profiles showing nuclear loss; 2 $=$ same as for score 1, but greater than one-third and less than two-thirds of the tubular profiles show nuclear loss; and $3=$ greater than two-thirds of tubular profiles showing nuclear loss. The total score for each kidney was calculated by the addition of all 100 scores, with a maximum possible score of 300 . The average number of infiltrating neutrophils was counted using 30 separate microscopic fields at a magnification of $\times 400$ at $24 \mathrm{~h}$ following reperfusion (Takahira et al. 2001).

\section{Statistical analysis}

All values are expressed as the mean \pm standard deviation (SD). Statistical analysis was performed using repeated-measure ANOVA for multiple comparisons when more than two groups were analyzed. Comparisons between the two groups were analyzed by the nonparametric Mann-Whitney $U$ test for uncorrelated pairs. A $p$ value $<0.05$ was considered statistically significant.

\section{Results}

$\alpha$-hANP reduces renal CINC-1 and MPO concentrations in rat renal I/R injury

As shown in Fig. 2A, renal ischemia/ reperfusion injury resulted in a marked increase in the CINC-1 concentrations, which increased from
A

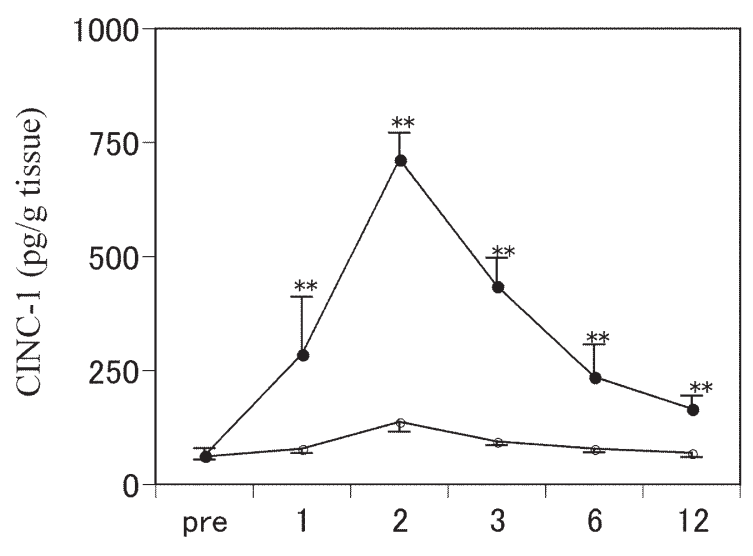

Time after reperfusion ( $h$ )

B

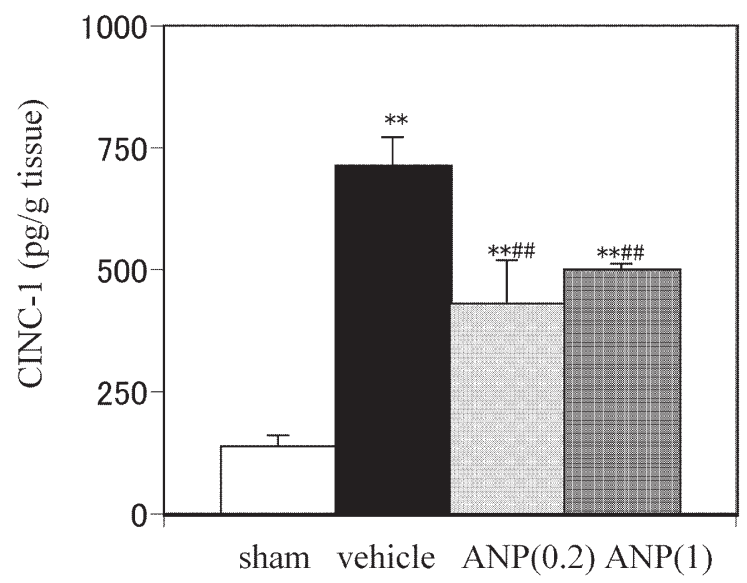

Fig. 2. Changes in the renal CINC-1 concentrations after renal I/R. (A)

Closed circles: vehicle group; open circles: sham group.

$* * p<0.01$ compared with the sham group.

Changes in the renal CINC-1 concentrations 2 $\mathrm{h}$ after renal $\mathrm{I} / \mathrm{R}$ in the three groups. (B)

Sham; sham group, vehicle; vehicle group, $\operatorname{ANP}(0.2)$; ANP group $(0.2 \mu \mathrm{g} / \mathrm{kg} / \mathrm{min})$, ANP(1); ANP group $(1 \mu \mathrm{g} / \mathrm{kg} / \mathrm{min})$.

${ }^{\# \#} p<0.01$ compared with the vehicle group.

$* * p<0.01$ compared with the sham group.

Data are expressed as the mean \pm S.D. $(n=8)$.

the pre-injury concentration $(63.6 \pm 15.6 \mathrm{pg} / \mathrm{g}$ tissue) to a peak of $722.0 \pm 48.5 \mathrm{pg} / \mathrm{g}$ tissue at $2 \mathrm{~h}$ after reperfusion, after which there was a gradually decrease to the pre-injury concentrations. The 
A

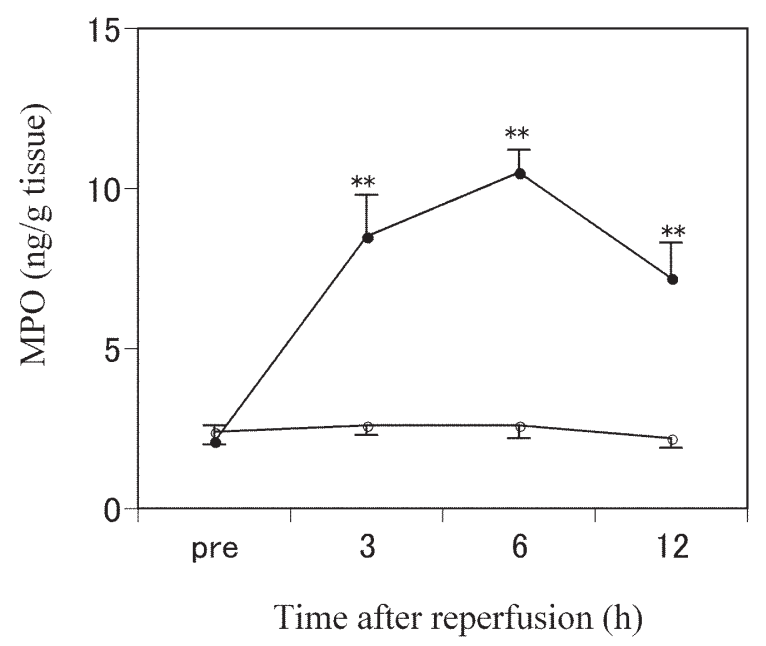

B

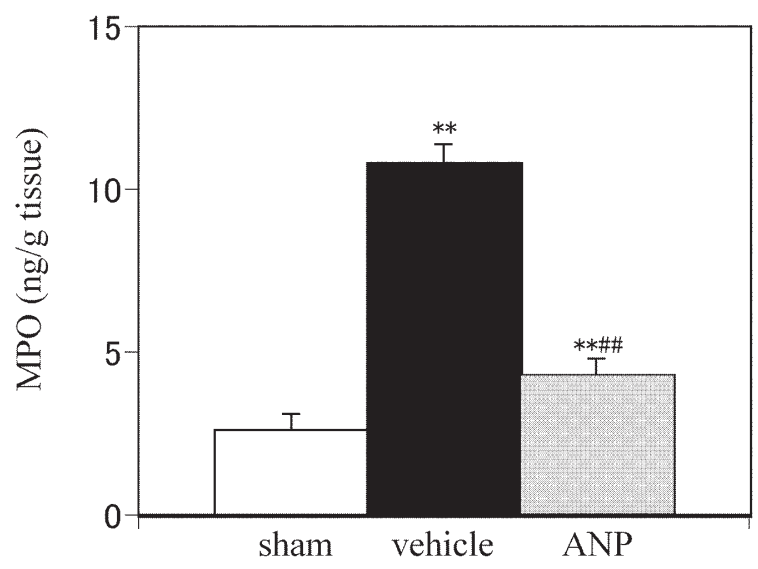

Fig. 3. Changes in the renal MPO concentrations after renal I/R. (A)

Closed circle: vehicle group; open circle: sham group.

$* * p<0.01$ compared with the sham group.

Changes in the renal MPO concentrations $6 \mathrm{~h}$ after renal I/R in the three groups. (B)

Sham; sham group, vehicle; vehicle group, ANP; ANP group $(0.2 \mu \mathrm{g} / \mathrm{kg} / \mathrm{min})$.

${ }^{\# \#} p<0.01$ compared with the vehicle group.

$* * p<0.01$ compared with the sham group.

Data are expressed as the mean \pm S.D. $(n=8)$.

renal CINC- 1 concentration in the ANP group $(0.2$ $\mu \mathrm{g} / \mathrm{kg} / \mathrm{min}$ ) was significantly decreased in comparison with the vehicle group at $2 \mathrm{~h}$ after $\mathrm{I} / \mathrm{R}$ ( $p=0.0008$, Fig. 2B). The renal CINC-1 concentration in the ANP group $(0.2 \mu \mathrm{g} / \mathrm{kg} / \mathrm{min})$ decreased in comparison with that seen in the ANP group $(1 \mu \mathrm{g} / \mathrm{kg} / \mathrm{min})$ at $2 \mathrm{~h}$ after reperfusion.

As shown in Fig. 3A, the MPO concentrations in the vehicle groups increased from the preinjury concentration $(2.1 \pm 0.5 \mathrm{ng} / \mathrm{g}$ tissue $)$ to a peak of $10.8 \pm 0.5 \mathrm{ng} / \mathrm{g}$ tissue at $6 \mathrm{~h}$ after reperfusion and then gradually decreased to the preinjury concentration of the vehicle group. The MPO concentration in the ANP group was significantly decreased $(p=0.0008)$, compared to the vehicle group, at $6 \mathrm{~h}$ after reperfusion (Fig. 3B).

Effects of $\alpha$-hANP on the changes on mean arterial blood pressure in rats

Mean arterial blood pressure in the ANP group ( $1 \mu \mathrm{g} / \mathrm{kg} / \mathrm{min})$ decreased in comparison to that seen in the ANP group $(0.2 \mu \mathrm{g} / \mathrm{kg} / \mathrm{min})$ during the ischemia/reperfusion (Fig. 4).

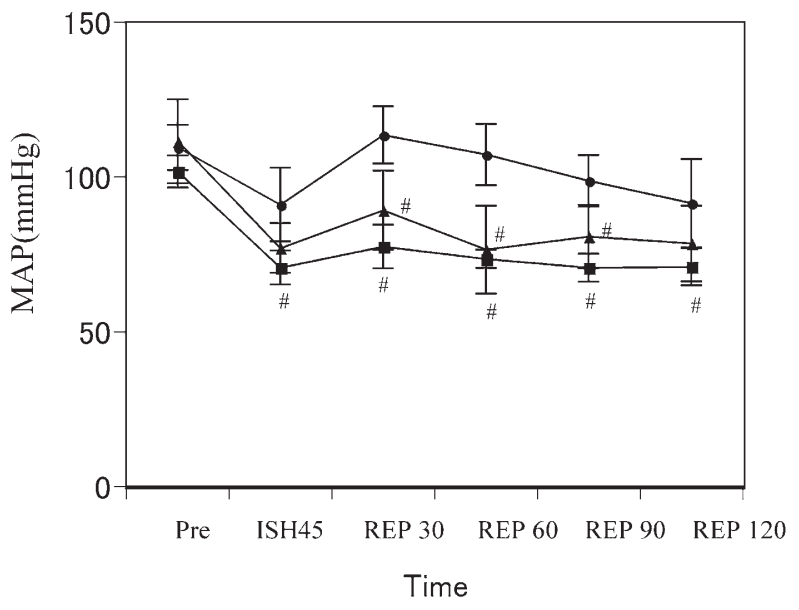

Fig. 4. Effects of $\alpha$-hANP on changes in mean arterial blood pressure during ischemia/ reperfusion.

Closed circles; vehicle group, closed triangles; ANP $0.2 \mu \mathrm{g} / \mathrm{kg} / \mathrm{min}$, closed squares; ANP $1 \mu \mathrm{g} / \mathrm{kg} / \mathrm{min}$.

ISH 45; ischemia 45 min, REP 30; reperfusion 30 min, REP 60; reperfusion 60 min, REP 90; reperfusion $90 \mathrm{~min}$, REP 120; reperfusion 120 $\min$.

${ }^{\#} p<0.05$ compared with the vehicle group. Data are expressed as the mean \pm S.D. $(n=4)$. 
$\alpha$-hANP reduces renal dysfunction mediated by $I / R$

The serum BUN and creatinine concentrations of the vehicle group and ANP group at preischemia were $23.9 \pm 1.4 \mathrm{mg} / \mathrm{dl}$ and $0.30 \pm 0.02$ $\mathrm{mg} / \mathrm{dl}, 24.2 \pm 3.0 \mathrm{mg} / \mathrm{dl}$ and $0.30 \pm 0.03 \mathrm{mg} / \mathrm{dl}$, respectively. The serum BUN and creatinine concentrations were significantly higher $(p=0.0008)$ in the rats that had suffered $I / R$ than in the rats that had a sham operation at $24 \mathrm{~h}$ after reperfusion, suggesting a significant degree of glomerular dysfunction. The intravenous administration of $\alpha$-hANP significantly inhibited the increase in the serum BUN and creatinine concentrations at $24 \mathrm{~h}$ after reperfusion in comparison with the vehicle group (Table 1). The urinary NAG concentrations were significantly higher in the rats that had suffered I/R as compared to the rats that had a sham operation at $24 \mathrm{~h}$ after reperfusion, suggesting a marked increase in tubular injury $(p=0.0008$, Table 1). In comparison with the urinary NAG in the vehicle group, the administration of $\alpha$-hANP produced a significant reduction in NAG, suggesting less tubular injury ( $p=0.0008$, Table 1$)$.

\section{$\alpha$-hANP reduces neutrophils in whole blood mediated by $I / R$}

The number of neutrophils in the vehicle group and ANP group at $24 \mathrm{~h}$ after reperfusion were $3,364 \pm 278 / \mu 1$ and $2,464 \pm 529 / \mu 1$, respectively. At $24 \mathrm{~h}$ after reperfusion, the number of neutrophils in the whole blood in the ANP group was decreased significantly $(n=5, p=0.009)$ as compared to the vehicle group.

\section{Effects of $\alpha$-hANP on I/R mediated renal histo- pathology}

In comparison with the normal tubular histology observed in the kidneys that were taken from the sham-operated rats (Fig. 5A), animals in the vehicle group demonstrated classic features of acute renal damage (Fig. 5B). These features include brush border loss, necrosis of tubular cells (arrows in Fig. 5B). When semiquantitatively compared with the total severity score that was measured from the kidneys obtained from the sham group, I/R in the vehicle group produced a significant increase in the total severity score ( $p=$ 0.02 , Table 2 ), which was significantly reduced by the administration of $\alpha$-hANP prior to I/R ( $p=$ 0.02 , Table 2).

The number of infiltrating neutrophils in the vehicle group was markedly increased at $24 \mathrm{~h}$ after $\mathrm{I} / \mathrm{R}$ as compared with the sham group ( $p=$ 0.02 , Table 2). Pretreatment with $\alpha$-hANP significantly reduced neutrophil infiltration as compared with the vehicle group ( $p=0.02$, Table 2).

\section{Discussion}

In this study, we demonstrated that $\alpha$-hANP significantly decreased renal CINC-1 and MPO production and attenuated renal dysfunction, as well as causing histopathologic changes in rats subjected to renal I/R.

The lower dose of $\alpha$-hANP $(0.2 \mu \mathrm{g} / \mathrm{kg} / \mathrm{min})$ reduced renal CINC-1 concentrations at $2 \mathrm{~h}$ after

TABle 1. Renal function data at $24 \mathrm{~h}$ following renal I/R.

\begin{tabular}{lccc}
\hline & $\begin{array}{c}\text { BUN }(\mathrm{mg} / \mathrm{dl}) \\
(n=8)\end{array}$ & $\begin{array}{c}\text { Creatinine }(\mathrm{mg} / \mathrm{dl}) \\
(n=8)\end{array}$ & $\begin{array}{c}\text { NAG }(\mathrm{U} / \mathrm{l}) \\
(n=8)\end{array}$ \\
\hline Sham group & $23.4 \pm 2.0$ & $0.30 \pm 0.02$ & $26.3 \pm 7.6$ \\
Vehicle group & $39.1 \pm 8.3^{\mathrm{a}}$ & $0.73 \pm 0.15^{\mathrm{a}}$ & $89.8 \pm 22.0^{\mathrm{a}}$ \\
ANP group & $30.0 \pm 4.1^{\mathrm{a}, \mathrm{b}}$ & $0.44 \pm 0.04^{\mathrm{a}, \mathrm{c}}$ & $39.0 \pm 12.2^{\mathrm{c}}$ \\
\hline
\end{tabular}

BUN: Blood urea nitrogen; NAG: $N$-acetyl $\beta$-d-glucosaminidase.

ANP group $(0.2 \mu \mathrm{g} / \mathrm{kg} / \mathrm{min})$.

${ }^{\mathrm{a}} p<0.01$ compared with the sham group.

${ }^{\mathrm{b}} p<0.05$ compared with the vehicle group.

${ }^{c} p<0.01$ compared with the vehicle group.

Data are expressed as the mean \pm S.D. 
A

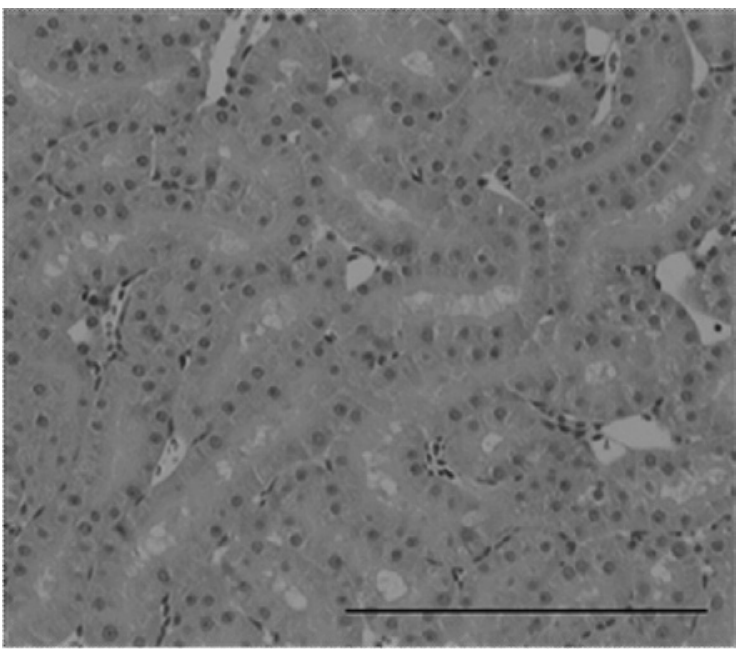

$\mathrm{B}$

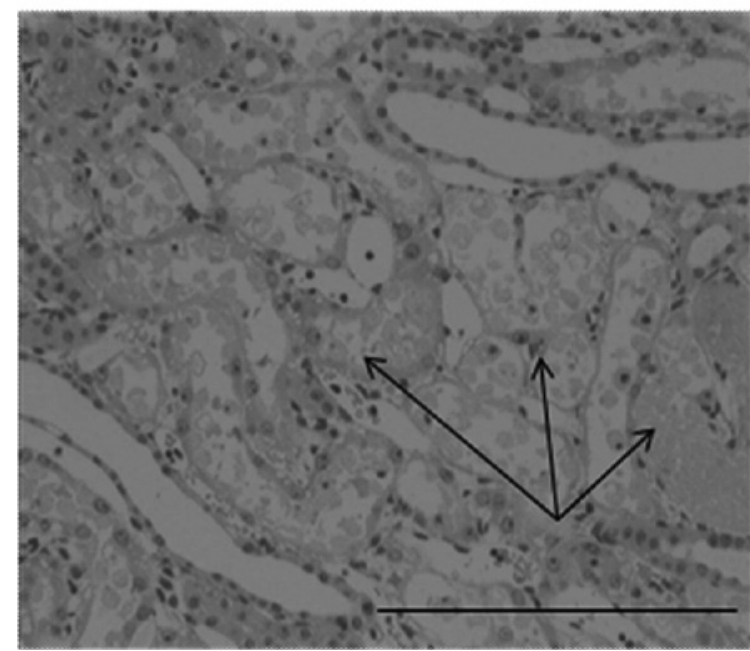

$\mathrm{C}$

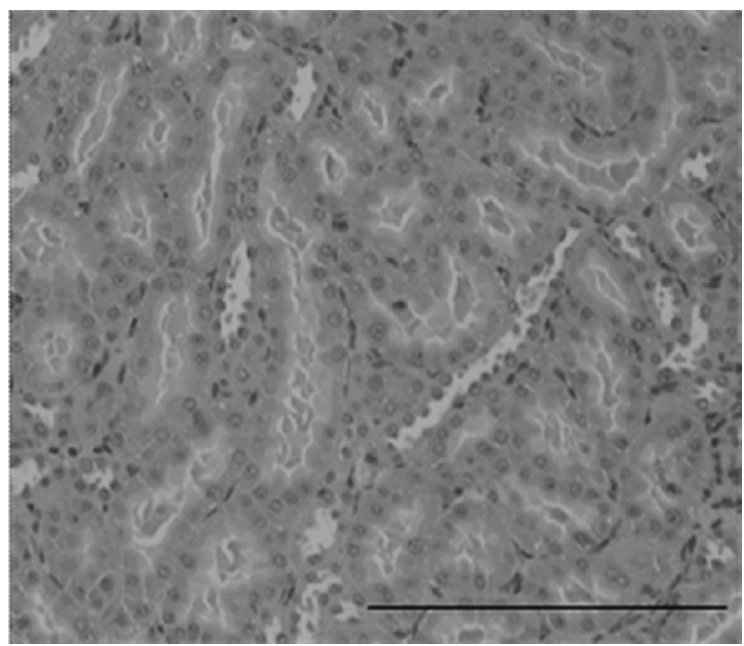

Fig. 5. Histopathologic evaluation $24 \mathrm{~h}$ after reperfusion.

Rats were subjected to 45 -min renal ischemia followed by reperfusion. Typical histopathological samples are shown for rats in the sham group (A), in the vehicle group (B), and ANP group $(0.2 \mu \mathrm{g} / \mathrm{kg} / \mathrm{min})(n=4$, each group) (C). Note the presence of the tubular necrosis (arrows in B). Original magnification, $\times 200$. The bar represents $200 \mu \mathrm{m}$.

TABLE 2. Total severity score and infiltrating neutrophils at $24 \mathrm{~h}$ following renal I/R.

\begin{tabular}{lcc}
\hline & $\begin{array}{c}\text { Total severity score } \\
(n=4)\end{array}$ & $\begin{array}{c}\text { Average number of neutrophils/field } \\
(n=4)\end{array}$ \\
\hline Sham group & $14.0 \pm 2.6$ & $0.09 \pm 0.03$ \\
Vehicle group & $155.8 \pm 17.1^{\mathrm{a}}$ & $1.43 \pm 0.24^{\mathrm{a}}$ \\
ANP group & $71.2 \pm 17.7^{\mathrm{a}, \mathrm{b}}$ & $0.3 \pm 0.07^{\mathrm{a}, \mathrm{b}}$ \\
\hline
\end{tabular}

The total severity score and the number of neutrophils per high-power field were counted in kidney samples obtained $24 \mathrm{~h}$ after I/R.

ANP group $(0.2 \mu \mathrm{g} / \mathrm{kg} / \mathrm{min})$.

${ }^{\mathrm{a}} p<0.05$ compared with the sham group.

${ }^{\mathrm{b}} p<0.05$ compared with the vehicle group.

Data are expressed as the mean \pm S.D. 
reperfusion in comparison with the higher dose of $\alpha$-hANP $(1 \mu \mathrm{g} / \mathrm{kg} / \mathrm{min})$. The mean arterial blood pressure of the lower dose of $\alpha$-hANP $(0.2 \mu \mathrm{g} / \mathrm{kg} /$ min) did not decrease in comparison with the higher dose of $\alpha$-hANP ( $1 \mu \mathrm{g} / \mathrm{kg} / \mathrm{min})$. This finding suggests that a lower dose of $\alpha$-hANP causes a smaller decrease in the blood pressure, and thus is more useful in clinical conditions compared to the use of a higher dose of $\alpha$-hANP.

ANP, a hormone synthesized by the cardiac atria, increases renal vasodilation and glomerular filtration rate by dilating the afferent arterioles and constricting the efferent arterioles to increase glomerular capillary hydraulic pressure (Lanese et al. 1991). ANP also induces redistribution of renal medullary blood flow (Davis and Briggs 1987). Furthermore, ANP has been shown to improve renal function in rats with ischemic acute renal failure by improving renal adenosine triphosphate regeneration after reperfusion (Nakamoto et al. 1987), thereby preserving the glomerular filtration rate and thus reducing renal tissue damage (Shaw et al. 1987). However, the mechanisms of the renoprotective effects of ANP remain unclear.

Renal I/R injury is a major cause of acute renal failure. The severity of the injury depends on the duration of the ischemia and the subsequent reperfusion periods. Acute ischemia elicits an inflammatory response characterized by the activation of neutrophils (Heinzelmann et al. 1999). Activation results in neutrophil adhesion to vascular endothelial cells and the entry of neutrophils into the extravascular space. Activated neutrophils have been shown to damage endothelial cells by releasing oxygen free radicals as well as neutrophil elastase (Harlan 1985). Furthermore, leukocytopenia does reduce I/R-induced renal injury, suggesting that leukocytes are critically involved in the pathologic process of this type of injury. Kelly et al. (1994) demonstrated that the inhibition of neutrophil adhesion prevents ischemic renal injury, which is consistent with this hypothesis. Furthermore, this concept was confirmed in the present study by the observation that renal CINC-1 and MPO were significantly increased after renal $\mathrm{I} / \mathrm{R}$. These inflammatory parameters associated with neutrophil activation were significantly reduced by $\alpha$-hANP, suggesting that this agent might reduce renal injury by reducing neutrophil activation. C-X-C chemokines, such as CINC-1 (Watanabe et al. 1992) and IL-8 (Middleton et al. 1997), have been implicated in the activation of neutrophils. Mononuclear phagocytes such as monocytes and macrophages appear to be the predominant cellular sources of IL-8 (Metinko et al. 1992), although this cytokine can also be produced by several nonimmune cells in response to the monocyte/macrophage-derived cytokine tumor necrosis factor (TNF) alpha and IL-1.

In this study, renal $\mathrm{I} / \mathrm{R}$ caused an elevation in kidney CINC- 1 concentrations. $\alpha$-hANP inhibited the increase in the renal CINC-1 concentration that peaked at $2 \mathrm{~h}$ after reperfusion. $\alpha$-hANP attenuates $\mathrm{I} / \mathrm{R}$ injury at least in part by reducing the activation of neutrophils in the kidney. TNF alpha production is enhanced in I/R-induced renal injury (Daemen et al. 1999). TNF alpha activates neutrophils to promote the release of inflammatory mediators like CINC-1. Nuclear factor kappa $\mathrm{B}(\mathrm{NF}-\kappa \mathrm{B})$ is an oxidant-sensitive transcription factor (Collart et al. 1990). Oxidant stress has been shown to activate NF- $\kappa \mathrm{B}$ and the activation of this transcription factor may play a role in the sequence of the ischemia/reperfusion induced TNF production (Meldrum et al. 1998). Although the precise mechanism by which $\alpha$-hANP reduces $\mathrm{I} / \mathrm{R}$-induced CINC-1 production is unknown, the inhibition of TNF alpha production upon decreased activation of NF- $\kappa$ B by $\alpha$-hANP may prevent the subsequent neutrophil activation that leads to an inhibition of renal injury. Kiemer et al. (2000) reported that ANP reduces the expression of TNF alpha mRNA during reperfusion of the rat liver upon decreased activation of $\mathrm{NF}_{-} \kappa \mathrm{B}$. However, further experimental studies in kidneys are required to elucidate the mechanisms by which $\alpha$-hANP reduces renal CINC-1 production.

Additional latent events are associated with the accumulation of leukocytes in peritubular capillaries and renal tissue. The adherence of leukocytes to the vascular endothelium is a critical early process in producing injury in ischemic tissues. 
After adherence and chemotaxis, neutrophils release reactive oxygen species, protease, elastase, MPO, and other enzymes that damage tissue (Okusa 2002). The MPO assay is widely used to quantify the number of neutrophils in a tissue and serves as an index of inflammation, as MPO is an enzyme that is released mainly from neutrophils. Because MPO activity is directly proportional to the tissue injury caused by I/R (Weiss 1989), we used MPO as an index of the renal accumulation of activated neutrophils from whole blood. In this study, renal I/R caused an elevation in the MPO concentration within $3 \mathrm{~h}$ after the initiation of reperfusion, indicating the presence of enhanced neutrophil infiltration in the inflamed tissue. In our study, $\alpha$-hANP administration before I/R prevented both the production of activated neutrophils in the blood and renal neutrophil infiltration. The decreased renal neutrophil infiltration may have contributed to the reduced renal injury after $\mathrm{I} / \mathrm{R}$ by reducing the cellular damage that results from the release of the neutrophil's proteolytic enzymes (proteases, elastases, and myeloperoxidases) and reactive oxygen species.

Adherent and activated neutrophils are known to cause vascular congestion and capillary plugging in the vasa recta of the outer medulla (Kelly et al. 1994; Okusa 2002). These phenomena lead to ischemia of the outer medulla, which subsequently causes tubular necrosis (Kelly et al. 1994). Consequently, live and dead cells slough into the lumen of the proximal tubules, contributing to cast formation. The cast reduces the glomerular filtration rate and leads to renal dysfunction after renal I/R (Bonventre 1993; Thadhani et al. 1996). Because ANP increases the single nephron glomerular filtration rate and renal solute excretion (Huang et al. 1985), it may prevent tubular obstruction by washing out the cellular debris. In this study, histopathology demonstrated that renal I/R caused acute renal tubular damage, consistent with the findings of an elevation in NAG (a specific indicator of proximal tubular function). The washing out of casts from the tubules by $\alpha$-hANP significantly prevented a decrease in the glomerular filtration rate, and therefore led to a lesser amount of renal dysfunc- tion and reduced the histopathologic damage observed.

Although this study establishes that the human form of ANP protects the kidney against $\mathrm{I} / \mathrm{R}$ injury, there is one limitation of the present study. Because the human form of ANP was used in an experimental model of ischemic renal dysfunction in the rat, it is unclear whether the 0.2 $\mu \mathrm{g} / \mathrm{kg} / \mathrm{min}$ dose of $\alpha$-hANP will be effective on renal function in clinical ischemic acute renal failure. Further studies on the exact dose of $\alpha$-hANP required for use in clinical ischemic acute renal failure will need to be undertaken to address this issue.

In conclusion, this study demonstrated that $\alpha$-hANP reduces I/R injury in rat kidneys, leading to improved renal function, a reduction in the histopathology of the renal tubular injury and inhibition of the activation of neutrophils, along with decreases in CINC-1 production and neutrophil infiltration. Thus, we speculate that suppression of neutrophil activation by $\alpha$-hANP may be responsible for its beneficial effects on $\mathrm{I} / \mathrm{R}$ injury in the rat kidney. However, further studies are required to definitively elucidate the mechanism by which $\alpha$-hANP reduces the I/R-induced CINC-1 production.

\section{Acknowledgments}

We are grateful to the Daiichi Sankyo Company (Tokyo) for supplying the $\alpha$-hANP that was used in this study.

\section{References}

Bonventre, J.V. (1993) Mechanisms of ischemic acute renal failure. Kidney Int., 43, 1160-1178.

Bradley, P.P., Priebat, D.A., Christensen, R.D. \& Rothstein, G. (1982) Measurement of cutaneous inflammation: estimation of neutrophil content with an enzyme marker. $J$. Invest. Dermatol., 78, 206-209.

Collart, M.A., Baeuerle, P. \& Vassalli, P. (1990) Regulation of tumor necrosis factor alpha transcription in macrophages: involvement of four kappa B-like motifs and of constitutive and inducible forms of NF-kappa B. Mol. Cell Biol., 10, 1498-506.

Daemen, M.A., van de Ven, M.W., Heineman, E. \& Buurman, W.A. (1999) Involvement of endogenous interleukin-10 and tumor necrosis factor-alpha in renal ischemia-reperfusion injury. Transplantation, 67, 792-800.

Davis, C.L. \& Briggs, J.P. (1987) Effect of atrial natriuretic peptides on renal medullary solute gradients. Am. J. Physiol., 253, F679-684. 
De Bold, A.J. (1979) Heart atria granularity effects of changes in water-electrolyte balance. Proc. Soc. Exp. Biol. Med., 161, 508-511.

Harlan, J.M. (1985) Leukocyte-endothelial interactions. Blood, 65, 513-525.

Heinzelmann, M., Mercer-Jones, M.A. \& Passmore, J.C. (1999) Neutrophils and renal failure. Am. J. Kidney Dis., 34, 384-399.

Huang, C.L., Lewicki, J., Johnson, L.K. \& Cogan, M.G. (1985) Renal mechanism of action of rat atrial natriuretic factor. $J$. Clin. Invest., 75, 769-773.

Kelly, K.J., Williams, W.W. Jr., Colvin, R.B. \& Bonventre, J.V. (1994) Antibody to intercellular adhesion molecule 1 protects the kidney against ischemic injury. Proc. Natl. Acad. Sci. USA, 91, 812-816.

Kiemer, A.K., Vollmar, A.M., Bilzer, M., Gerwig, T. \& Gerbes, A.L. (2000) Atrial natriuretic peptide reduces expression of TNF-alpha mRNA during reperfusion of the rat liver upon decreased activation of NF-kappaB and AP-1. J. Hepatol., 33, 236-246.

Lanese, D.M., Yuan, B.H., Falk, S.A. \& Conger, J.D. (1991) Effects of atriopeptin III on isolated rat afferent and efferent arterioles. Am. J. Physiol., 261, F1102-1109.

McWhinnie, D.L., Thompson, J.F., Taylor, H.M., Chapman, J.R., Bolton, E.M., Carter, N.P., Wood, R.F. \& Morris, P.J. (1986) Morphometric analysis of cellular infiltration assessed by monoclonal antibody labeling in sequential human renal allograft biopsies. Transplantation, 42, 352-358.

Meldrum, D.R. (1998) Tumor necrosis factor in the heart. Am. J. Physiol., 274, R577-595.

Metinko, A.P., Kunkel, S.L., Standiford, T.J. \& Strieter, R.M. (1992) Anoxia-hyperoxia induces monocyte-derived interleukin-8. J. Clin. Invest., 90, 791-798.

Middleton, J., Neil, S., Wintle, J., Clark-Lewis, I., Moore, H., Lam, C., Auer, M., Hub, E. \& Rot, A. (1997) Transcytosis and surface presentation of IL- 8 by venular endothelial cells. Cell, 91, 385-395.

Nakamoto, M., Shapiro, J.I., Shanley, P.F., Chan, L. \& Schrier, R.W. (1987) In vitro and in vivo protective effect of atriopeptin III on ischemic acute renal failure. J. Clin. Invest., 80, 698-705.

Okusa, M.D. (2002) The inflammatory cascade in acute isch- emic renal failure. Nephron, 90, 133-138.

Rahman, S.N., Kim, G.E., Mathew, A.S., Goldberg, C.A., Allgren, R., Schrier, R.W. \& Conger, J.D. (1994) Effects of atrial natriuretic peptide in clinical acute renal failure. Kidney Int., 45, 1731-1738.

Saito, Y., Nakao, K., Nishimura, K., Sugawara, A., Okumura, K., Obata, K., Sonoda, R., Ban, T., Yasue, H. \& Imura, H. (1987) Clinical application of atrial natriuretic polypeptide in patients with congestive heart failure: beneficial effects on left ventricular function. Circulation, 76, 115-124.

Shaw, S.G., Weidmann, P., Hodler, J., Zimmermann, A. \& Paternostro, A. (1987) Atrial natriuretic peptide protects against acute ischemic renal failure in the rat. J. Clin. Invest., 80, 1232-1237.

Takada, M., Nadeau, K.C., Shaw, G.D., Marquette, K.A. \& Tilney, N.L. (1997) The cytokine-adhesion molecule cascade in ischemia/reperfusion injury of the rat kidney. Inhibition by a soluble P-selectin ligand. J. Clin. Invest., 99, 2682-2690.

Takahira, R., Yonemura, K., Fujise, Y. \& Hishida, A. (2001) Dexamethasone attenuates neutrophil infiltration in the rat kidney in ischemia/reperfusion injury: the possible role of nitroxyl. Free Radic. Biol. Med., 31, 809-815.

Thadhani, R., Pascual, M. \& Bonventre, J.V. (1996) Acute renal failure. N. Engl. J. Med., 334, 1448-1460.

Valsson, F., Ricksten, S.E., Hedner, T., Zall, S., William-Olsson, E.B. \& Lundin, S. (1994) Effects of atrial natriuretic peptide on renal function after cardiac surgery and in cyclosporine-treated heart transplant recipients. J. Cardiothorac. Vasc. Anesth., 8, 425-430.

Watanabe, K., Suematsu, M., Iida, M., Takaishi, K., Iizuka, Y., Suzuki, H., Suzuki, M., Tsuchiya, M. \& Tsurufuji, S. (1992) Effect of rat CINC/gro, a member of the interleukin-8 family, on leukocytes in microcirculation of the rat mesentery. Exp. Mol. Pathol., 56, 60-69.

Weiss, S.J. (1989) Tissue destruction by neutrophils. N. Engl. J. Med., 320, 365-376.

Williams, P., Lopez, H., Britt, D., Chan, C., Ezrin, A. \& Hottendorf, R. (1997) Characterization of renal ischemiareperfusion injury in rats. J. Pharmacol. Toxicol. Methods, 37, 1-7. 